\title{
Improving the Energy Yield of Plasma-Based Ammonia Synthesis with In Situ Adsorption
}

\author{
Kevin H. R. Rouwenhorst,* Samuel Mani, and Leon Lefferts* \\ Cite This: https://doi.org/10.1021/acssuschemeng.1c08467 \\ Read Online
}

ABSTRACT: Plasma-based ammonia synthesis is studied as an option for electrifying the chemical industry. However, the energy efficiency of plasma-based ammonia synthesis is severely limited by ammonia decomposition in the plasma phase. We show that the use of zeolite $4 \mathrm{~A}$ as an adsorbent for in situ ammonia removal from the plasma phase suppresses product decomposition, thereby increasing the ammonia yield. It is found that the ammonia yield for plasmachemical ammonia synthesis with in situ ammonia removal is improved by a factor of 2 compared to steady-state plasma-chemical ammonia synthesis. Plasma-induced surface heating limits the effective ammonia adsorption capacity of the zeolite, decreasing the adsorption capacity. In situ product removal is of interest for plasma chemistry and plasma catalysis, in general, as the product decomposition in the

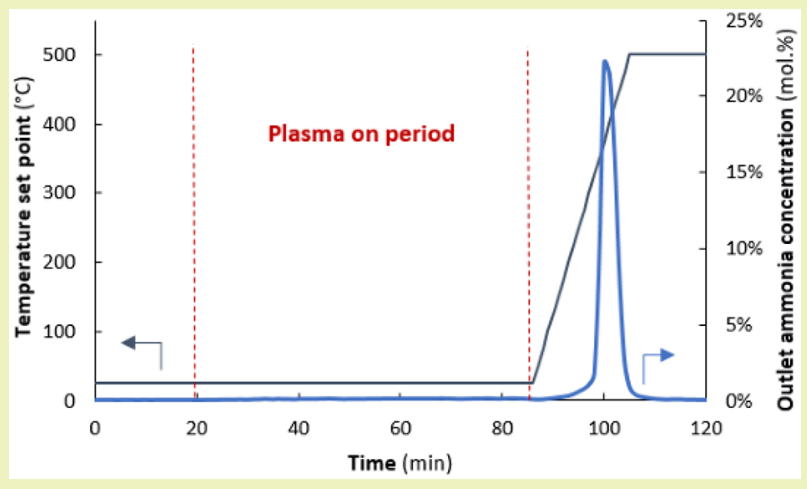
plasma is a general phenomenon limiting the product yield.

KEYWORDS: Ammonia synthesis, Plasma chemistry, Zeolite, In situ product removal, Adsorption

\section{INTRODUCTION}

A circular economy with renewable energy sources is required to decrease greenhouse emissions. ${ }^{1}$ However, most renewable energy sources are intermittent, which leads to the requirement for energy storage. Among the storage options, chemical storage in the form of hydrogen $\left(\mathrm{H}_{2}\right)$ and hydrogen carriers is the only feasible option for seasonal energy storage. ${ }^{2}$ As hydrogen is difficult to store and transport, ${ }^{3}$ hydrogen carriers are proposed. ${ }^{4-8}$ Ammonia $\left(\mathrm{NH}_{3}\right)$ is one of these hydrogen carriers, ${ }^{2,5,9-14}$ formed through the reaction of hydrogen with atmospheric nitrogen $\left(\mathrm{N}_{2}\right)$.

With the emergence of low cost electricity from renewables, electrification of chemical reactions is imminent. ${ }^{15}$ Therefore, plasma-catalytic ammonia synthesis has recently gained interest. $^{16-19}$ However, the reaction mechanisms and the relevant process parameters are not fully understood. ${ }^{20-22}$ The best reported energy yield for plasma-catalytic ammonia synthesis is $37.9 \mathrm{~g}-\mathrm{NH}_{3} \mathrm{kWh}^{-1},{ }^{23}$ and most studies report an energy yield below $5 \mathrm{~g}-\mathrm{NH}_{3} \mathrm{kWh}_{3} \mathrm{kWh}^{-1}{ }^{18,19}$ for example, beow the benchmark of $150-200 \mathrm{~g}-\mathrm{NH}_{3} \mathrm{kWh}^{-1}$ required for commercialization. $^{24,25}$

The low energy yields are in part due to ammonia decomposition by the plasma. Recently, van ' $t$ Veer et al. ${ }^{26}$ suggested that the ammonia formed in the plasma is also decomposed by the plasma, based on modeling studies with gas phase reactions and surface reactions. The authors reported that ammonia is decomposed during the microdischarges via electron impact dissociation, while ammonia is formed from $\mathrm{N}$ and $\mathrm{H}$ radicals during the afterglow. Further experimental evidence was provided by Navascués et al., ${ }^{27,28}$ who demonstrated with isotope labeling studies that ammonia is decomposed in the plasma by electron impact dissociation. ${ }^{28}$ In conclusion, plasma decomposition of ammonia significantly limits the energy yield for ammonia formation in the plasma.

In situ removal of ammonia from the plasma phase might offer a solution for this challenge. Solid acids such as zeolites can be used to remove ammonia from a gas mixture via adsorption. $^{29,30}$ Therefore, we propose to use zeolites for in situ ammonia removal from the plasma phase in the current work, as zeolites are stable solid materials. Zeolite $4 \mathrm{~A}$ is used as a case study in the current work.

Peng et al. ${ }^{31}$ also showed that $\mathrm{MgCl}_{2}$ can be used to absorb ammonia during plasma-chemical ammonia synthesis. A drawback of this method is the limited stability of $\mathrm{MgCl}_{2}$, forming $\mathrm{MgN}_{2}$ during plasma operation. The zeolite used in the current work is more chemically stable against changes in chemical compositions with nitrogen species.

Zeolites were previously researched for plasma-based ammonia synthesis by Gorky et al. ${ }^{32}$ and Shah et al. ${ }^{33}$

Received: December 16, 2021

Revised: January 29, 2022 
However, the authors report on steady-state ammonia production rates over zeolite $5 \mathrm{~A}$ and zeolite beta in the presence of a plasma, rather than the effect of the in situ ammonia adsorption on the zeolite. The authors reported a higher steady-state ammonia production rate for zeolite 5A and zeolite beta as compared to other oxides, such as silica and alumina. ${ }^{32,33}$ In the current work, we observe that the ammonia yield produced with in situ ammonia removal from the plasma zone is about two times that of the steady-state experiments. This demonstrates that in situ ammonia removal from the plasma zone is able to suppress ammonia decomposition by the plasma, thereby increasing the overall ammonia formation rate.

\section{RESULTS AND DISCUSSION}

The experimental procedures and details can be found in the Supporting Information. In this section, the results and discussion for the in situ removal of ammonia by zeolite $4 \mathrm{~A}$ are presented. Temperature-programmed desorption (TPD) results in absence of plasma can be found in the Supporting Information. The results of the sorbent characterization with BET analysis, XRF, XRD, and plasma characterization with Lissajous plots and UV-vis spectroscopy can be found in the Supporting Information.

Plasma-Based Ammonia Synthesis with In Situ Adsorption. Plasma-based ammonia synthesis was studied in the presence of a packed bed with zeolite $4 \mathrm{~A}$ particles with diameters of $250-300 \mu \mathrm{m}$. The plasma reactor is a dielectric barrier discharge (DBD) reactor operating at atmospheric pressure. Ammonia adsorbs on the zeolite until saturation, after which the zeolite cannot adsorb additional ammonia, and the ammonia concentration in the reactor outlet increases to a steady-state value.

The ammonia concentration in the outlet as a function of time is shown in Figure 1, for a $\mathrm{H}_{2}: \mathrm{N}_{2}$ ratio of $1: 4$ and at a

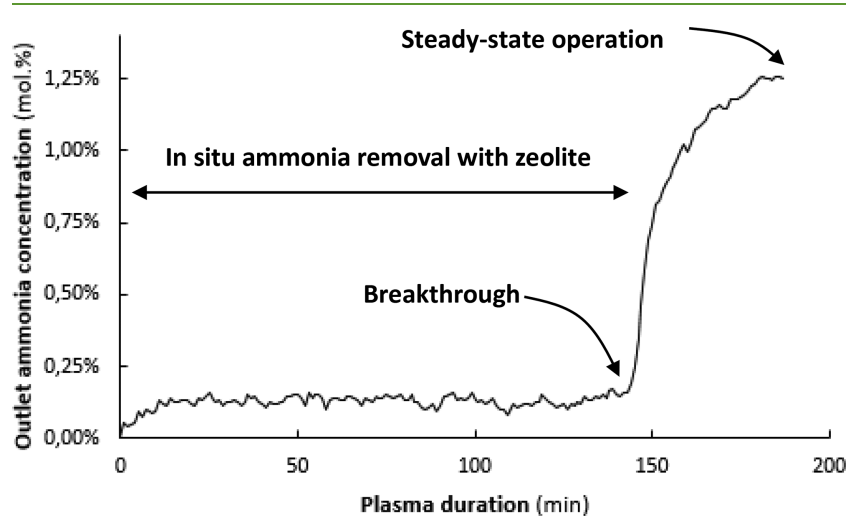

Figure 1. Outlet ammonia concentration as a function of the plasma duration. Oven temperature set point, $25{ }^{\circ} \mathrm{C}$; total flow rate, $10 \mathrm{~mL}$ $\min ^{-1} ; \mathrm{H}_{2}: \mathrm{N}_{2}=1$ :4; plasma power, $6.4 \mathrm{~W}\left(\mathrm{SIE}=38.4 \mathrm{~kJ} \mathrm{~L}^{-1}\right)$; zeolite loading, $600 \mathrm{mg}(250-300 \mu \mathrm{m})$.

constant flow rate of $10 \mathrm{~mL} \mathrm{~min}{ }^{-1}$ and a constant plasma power of $6.4 \mathrm{~W}$, for example, a SEI (specific energy input) of $38.4 \mathrm{~kJ} \mathrm{~L} \mathrm{~L}^{-1}$. The corresponding Lissajous plot is shown in Figure S3. It is observed that the ammonia outlet concentration is about $0.1-0.2 \mathrm{~mol} \%$ during the first 145 min and increases to about $1.3 \mathrm{~mol} \%$ afterward.

The change in ammonia outlet concentration after $145 \mathrm{~min}$ in Figure 1 is attributed to saturation of the zeolite, resulting in breakthrough of the ammonia in the outlet. To test this hypothesis, the plasma was turned off, and the reactor was heated to desorb ammonia from the zeolite (Figure 2). Ammonia was desorbed from the zeolite in absence of the plasma in pure $\mathrm{N}_{2}$ at $10 \mathrm{~mL} \mathrm{~min}^{-1}$, and the reactor was heated at a rate of $25{ }^{\circ} \mathrm{C} \mathrm{min}^{-1}$. A typical result is shown in Figure 2. It is observed that ammonia is indeed desorbed from the zeolite. This confirms the in situ adsorption of ammonia on the zeolite during the plasma-chemical ammonia synthesis.

Figure 3 a shows the amount of ammonia desorbed while varying the plasma duration, at a constant flow of $10 \mathrm{~mL} \mathrm{~min}^{-1}$ and a constant plasma power of 6.4 W. As shown in Figure 3b, the amount of desorbed ammonia scales linearly with the plasma duration for short plasma durations for several different $\mathrm{H}_{2}: \mathrm{N}_{2}$ ratios. The amount of adsorbed ammonia stabilizes at about 2.4 mmol- $\mathrm{NH}_{3}$ g-zeolite ${ }^{-1}$ for all $\mathrm{H}_{2}: \mathrm{N}_{2}$ ratios. This coincides with the plasma duration required to cause ammonia breakthrough (Figure 1), confirming that the zeolite is saturated with ammonia, and the outlet ammonia concentration increases to a steady-state value.

Figure 4 compares the amount of ammonia produced in the first 5 min of plasma-based ammonia synthesis with in situ ammonia removal, i.e. remote from any saturation effects (Figure $3 b$ ), with the amount of ammonia produced in the same time during steady-state plasma-based ammonia synthesis. The steady-state plasma-based ammonia synthesis yield over $5 \mathrm{~min}$ is calculated from the steady-state ammonia outlet concentration, for example, after zeolite saturation. The amount of ammonia produced by in situ removal operation is typically two times the amount of ammonia formed during steady-state operation, indicating a beneficial effect of adsorbing ammonia on zeolite 4A. Furthermore, the ammonia yield is found to be highest for $\mathrm{H}_{2}: \mathrm{N}_{2}$ ratios of $1: 1$ and 1:2 during $5 \mathrm{~min}$ of plasma illumination, both for steady-state operation and plasma-based ammonia synthesis with in situ ammonia removal, in line with observations in the literature for steady-state operation at relatively high plasma powers. ${ }^{16}$ It should be noted that the optimal $\mathrm{H}_{2}: \mathrm{N}_{2}$ ratio shifts to more $\mathrm{N}_{2}$-rich values when extending the plasma illumination time to, for example, 75 min, as shown in Figure S7, consistent with the data in Figure 3b. This can be attributed to more extended heating of the zeolite during longer exposure to plasma, which apparently decreases the rate of $\mathrm{NH}_{3}$ adsorption for $\mathrm{H}_{2}$-rich plasmas.

The highest energy yield for plasma-based ammonia synthesis is about $2.3 \mathrm{~g}-\mathrm{NH}_{3} \mathrm{kWh}^{-1}$ for a $\mathrm{H}_{2}: \mathrm{N}_{2}$ ratio of $1: 2$ and a plasma power of $6.4 \mathrm{~W}$. This is about a factor of 2 better than the energy yield for steady-state operation, i.e., $1.1 \mathrm{~g}-\mathrm{NH}_{3}$ $\mathrm{kWh}^{-1}$. This improvement is significant and demonstrates the necessity of product removal from plasma-chemical synthesis. The energy consumption of zeolite regeneration is found to be negligible as compared to the plasma energy input (Section S2.6, Supporting Information).

It should be noted that this is still far below the benchmark of $150-200 \mathrm{~g}-\mathrm{NH}_{3} \mathrm{kWh}^{-1}$ required for commercialization of plasma-based ammonia synthesis for small-scale applications ( $\mathrm{kW}$ range). ${ }^{24,25}$ This benchmark is based on the energy consumption of a small-scale Haber-Bosch ammonia synthesis loop. ${ }^{5,24}$ The highest energy yield so far reported is $37.9 \mathrm{~g}-\mathrm{NH}_{3}$ $\mathrm{kWh}^{-1}$ for plasma-driven ammonia synthesis with a Ru-based catalyst. ${ }^{23,34}$ Note that the goal of this work is not to achieve the highest energy yield but to demonstrate the positive effect of in situ ammonia adsorption. ${ }^{23}$ 


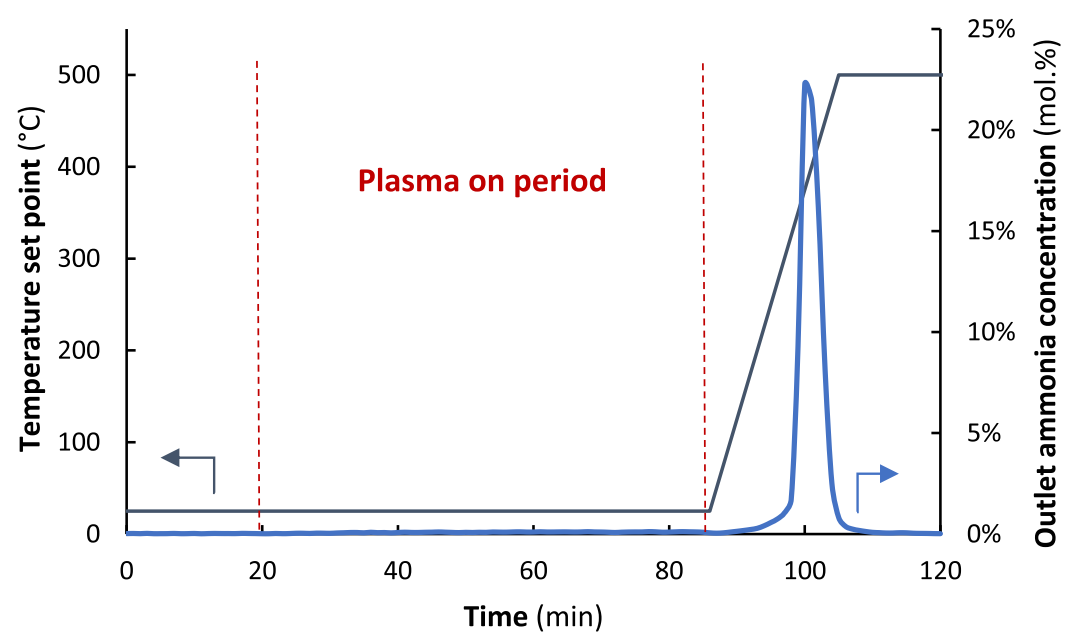

Figure 2. Example experiment for plasma-based ammonia synthesis with in situ adsorption. Reactor temperature (left axis) and outlet ammonia MS signal (right axis) as a function of time. Oven temperature set point during plasma, $25^{\circ} \mathrm{C}$; total flow rate, $10 \mathrm{~mL} \mathrm{~min}^{-1}$; $\mathrm{H}_{2}: \mathrm{N}_{2}=1: 4 ;$ plasma power, $6.4 \mathrm{~W}\left(\mathrm{SIE}=38.4 \mathrm{~kJ} \mathrm{~L}^{-1}\right)$; zeolite loading, $600 \mathrm{mg}(250-300 \mu \mathrm{m})$; plasma duration, $67 \mathrm{~min}$; heating rate after plasma-based ammonia synthesis, $25{ }^{\circ} \mathrm{C} \min ^{-1}$; pure $\mathrm{N}_{2}, 10 \mathrm{~mL} \mathrm{~min}^{-1}$.
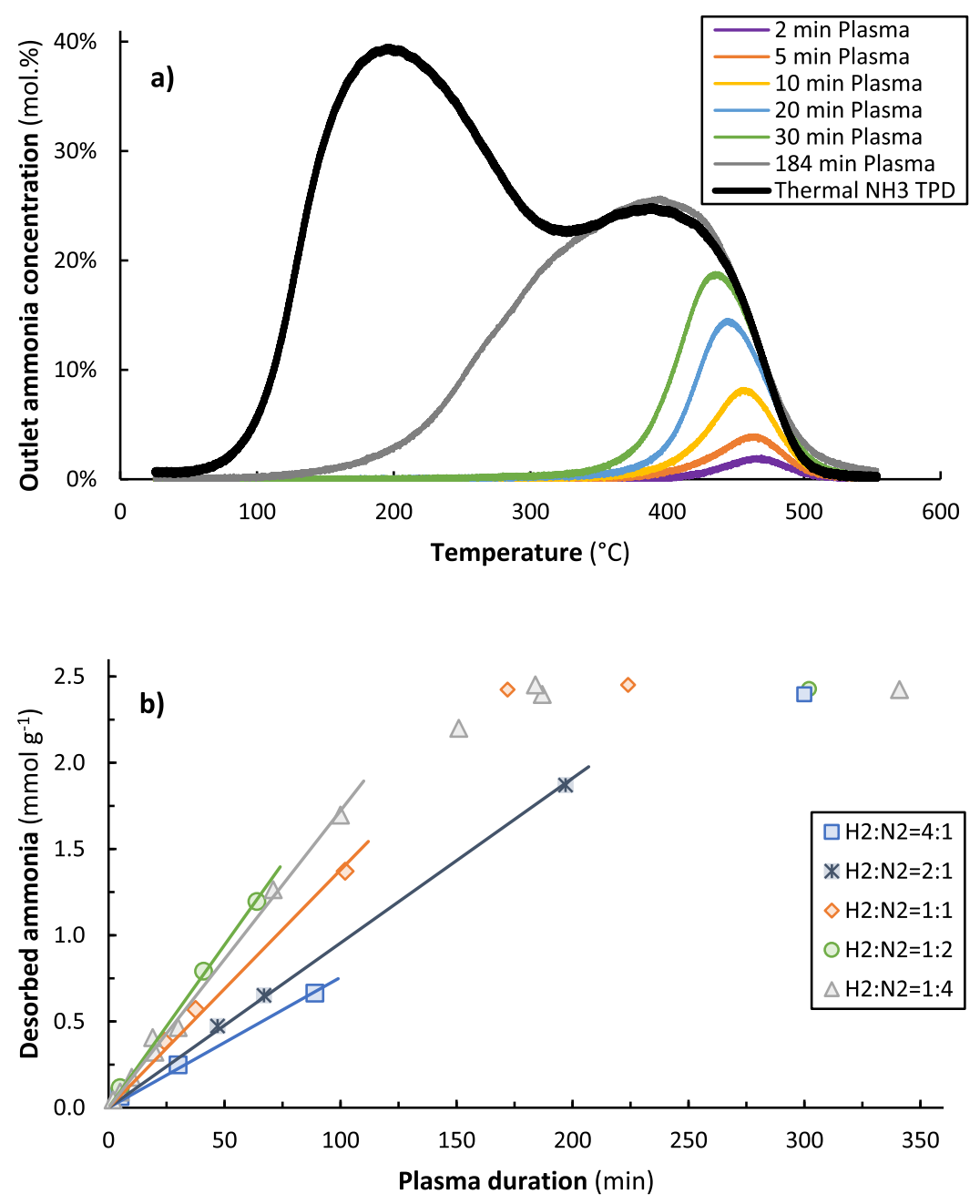

Figure 3. Effect of plasma duration on the amount of ammonia adsorbed on the zeolite. (a) Thermal ammonia TPD signal after ammonia adsorption in absence of plasma $\left(2.0 \mathrm{~mol} \% \mathrm{NH}_{3}\right.$ in $\left.\mathrm{N}_{2}, 10 \mathrm{~mL} \mathrm{~min}{ }^{-1}\right)$. Ammonia TPD signal after plasma-based ammonia synthesis with in situ removal (total flow rate, $10 \mathrm{~mL} \mathrm{~min}^{-1} ; \mathrm{H}_{2}: \mathrm{N}_{2}=1: 4$; plasma power, $6.4 \mathrm{~W}$ for various plasma durations). Ammonia desorption in absence of plasma in pure $\mathrm{N}_{2}$ at $10 \mathrm{~mL} \mathrm{~min}^{-1}$; heating rate, $25{ }^{\circ} \mathrm{C} \mathrm{min}^{-1}$. (b) Effect of plasma duration on the amount of ammonia desorbed for various $\mathrm{H}_{2}: \mathrm{N}_{2}$ ratios during plasma. 


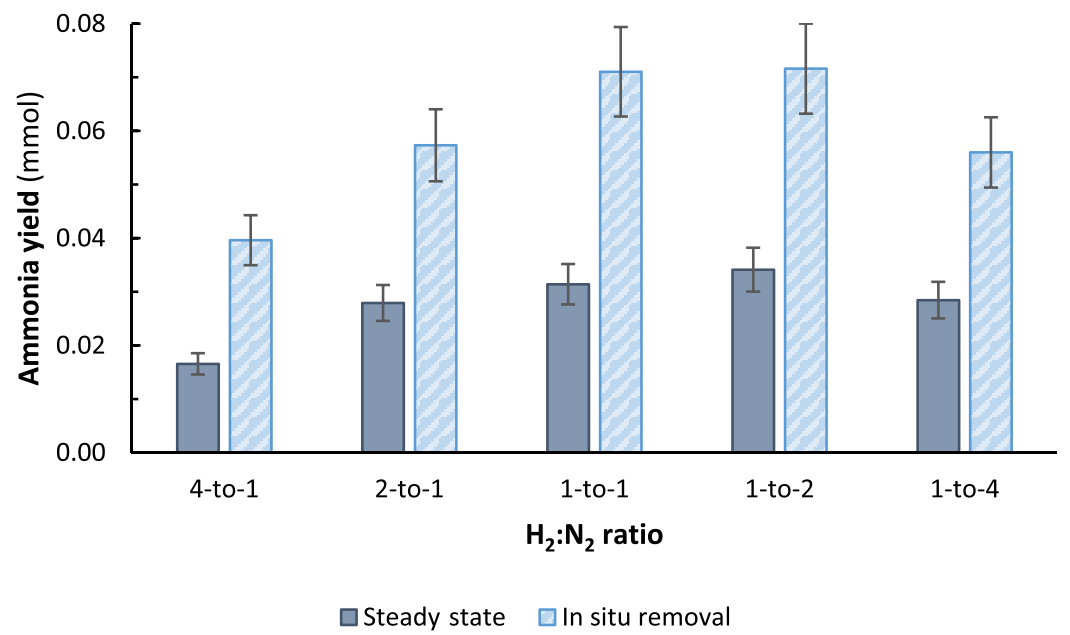

Figure 4. Comparison of cumulative ammonia yield after $5 \mathrm{~min}$ of plasma for steady-state operation (dark bluw columns) and in situ ammonia removal (light blue columns), varying $\mathrm{H}_{2}: \mathrm{N}_{2}$ ratios. Oven temperature set point, $25{ }^{\circ} \mathrm{C}$; total flow rate, $10 \mathrm{~mL} \mathrm{~min}^{-1}$; plasma power, $6.4 \mathrm{~W}(\mathrm{SIE}=$ $\left.38.4 \mathrm{~kJ} \mathrm{~L}^{-1}\right)$; zeolite loading, $600 \mathrm{mg}(250-300 \mu \mathrm{m})$; ammonia desorption in absence of plasma in pure $\mathrm{N}_{2}$ at $10 \mathrm{~mL} \mathrm{~min}^{-1}$; heating rate, $25^{\circ} \mathrm{C}$ $\min ^{-1}$.

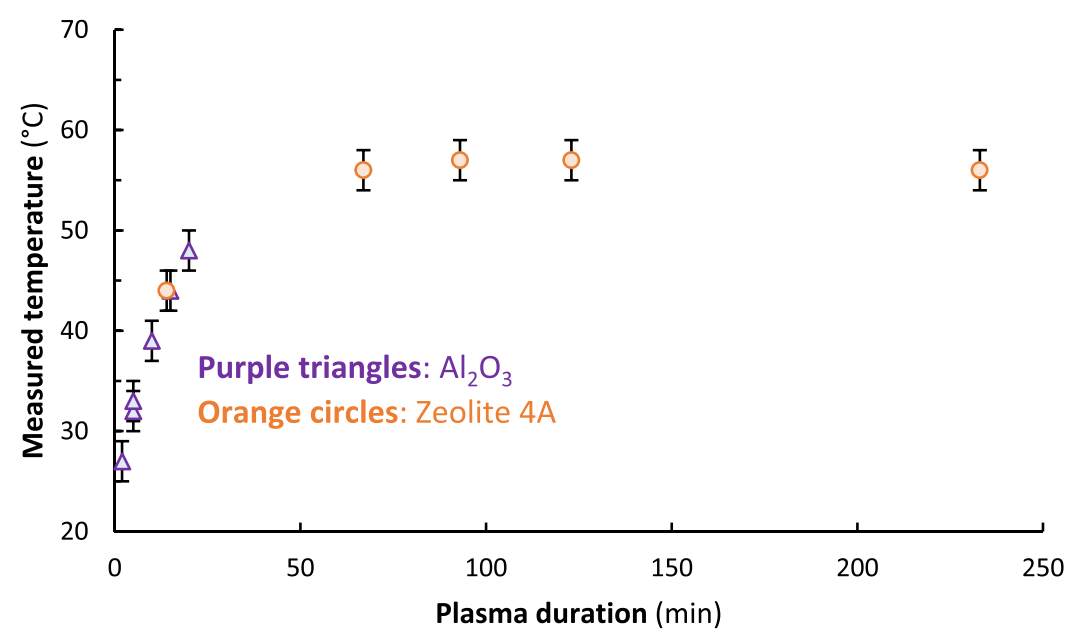

Figure 5. Temperature at the outside of the reactor as a function of the plasma duration. Oven temperature set point, $25^{\circ} \mathrm{C}$; total flow rate, $10 \mathrm{~mL}$ $\mathrm{min}^{-1}$; plasma power, $6.4 \mathrm{~W}\left(\mathrm{SIE}=38.4 \mathrm{~kJ} \mathrm{~L}^{-1}\right) ; \mathrm{H}_{2}: \mathrm{N}_{2}=1: 4$; zeolite/alumina loading, $600 \mathrm{mg}(250-300 \mu \mathrm{m})$.

Plasma-Zeolite Interactions. It cannot be ruled out that the zeolite also influences the chemical reactions taking place in the reactor. Zeolites dissociate neither $\mathrm{N}_{2}$ nor $\mathrm{H}_{2}$ and have no activity for ammonia synthesis under thermal conditions. ${ }^{35}$ Nevertheless, the external zeolite surface may interact with $\mathrm{H}$ and $\mathrm{N}$ radicals in the plasma, possibly enabling reactions between activated species in the plasma with adsorbed radicals. However, the differences between operation with unsaturated zeolite and the steady-state performance after reaching saturation are clearly due to the effect of ammonia adsorption.

The macroscopic zeolite particles sized with radii between 125 and $150 \mu \mathrm{m}$ contain internal pores between the primary zeolite particles smaller than $0.1 \mu \mathrm{m}$, while the zeolite cages have even smaller sizes in the subnanometer range. Plasma cannot form inside pores with diameters below typically $1-10$ $\mu \mathrm{m} .{ }^{36-40}$ According to Paschen's law, the breakdown voltage is determined by the product of the electrode distance and the pressure, so that plasma cannot form in submicrometer pores. ${ }^{36,40}$

Plasma radicals such as $\mathrm{N}$ and $\mathrm{NH}$ formed outside pores may penetrate into pores via diffusion up to typically $1 \mu \mathrm{m}$, based on the lifetime of such species and their diffusivity. ${ }^{41}$ The resulting penetration depth is typically $1 \mu \mathrm{m}$ for plasma radicals, much smaller than the radius of the zeolite $4 \mathrm{~A}$ particles of $125-150 \mu \mathrm{m}$, as used in this work. Thus, the vast majority of the zeolites pores are not accessible for plasma species. Therefore, adsorbed ammonia is not in contact with the plasma and thereby protected against the plasma. The ammonia concentration in the intraparticle spaces is decreased from typically $1.3 \%$ to about $0.15 \%$ (Figure 1), diminishing ammonia decomposition by the plasma through, for instance, electron-impact dissociation, an important pathway for ammonia decomposition in a DBD reactor. ${ }^{28}$ In conclusion, the higher ammonia production by in situ ammonia removal operation as compared to steady-state operation can be attributed to decreased ammonia decomposition in the plasma phase.

Effect of Heating. As shown in Figure 3a, the total ammonia desorbed from the zeolite after plasma-based ammonia synthesis $\left(2.4 \mathrm{mmol}-\mathrm{NH}_{3} \mathrm{~g}^{-1}\right)$ is lower than in the case of ammonia TPD after adsorption of ammonia at ambient temperature and for $2 \mathrm{~mol} \% \mathrm{NH}_{3}$ in $\mathrm{N}_{2}$ at atmospheric 
pressure $\left(6.3 \mathrm{mmol}-\mathrm{NH}_{3} \mathrm{~g}^{-1}\right)$. For the thermal ammonia TPD study, two peaks can be identified: the first at $200{ }^{\circ} \mathrm{C}$ and the second at $400{ }^{\circ} \mathrm{C}$. The peak at $400{ }^{\circ} \mathrm{C}$ is attributed to strongly bound ammonia through electrostatic attraction between $\mathrm{Na}^{+}$ and the lone electron pair of ammonia. ${ }^{42}$ The peak at $200{ }^{\circ} \mathrm{C}$ is attributed to physisorbed $\mathrm{NH}_{3}{ }^{43}$ Exclusively, the peak at 400 ${ }^{\circ} \mathrm{C}$ is observed after plasma-based ammonia synthesis. This indicates that only strongly bound ammonia is detected, while physisorbed ammonia is not observed. This suggests that the zeolite is heated, preventing physisorption of ammonia. Plasmas contain highly energetic species, and heat is dissipated by collisions with the surface as well as by recombination of plasma species. $^{25,44}$

To test the hypothesis of reactor heating, the temperature at the outside of the plasma reactor was measured for various plasma durations using a thermocouple (Section S1.4, Supporting Information). The temperature of the oven was regulated at $25{ }^{\circ} \mathrm{C}$. As shown in Figure 5, the measured temperature at the outside of the reactor increases upon plasma illumination, stabilizing at about $57^{\circ} \mathrm{C}$. This confirms that the plasma heats the reactor. It should be noted that the temperature inside the plasma reactor is probably higher than outside the plasma reactor. ${ }^{41,45,46}$ As follows from the adsorption isotherm for zeolite 4A Figure S6), a temperature of about $145{ }^{\circ} \mathrm{C}$ is required to attain an ammonia capacity of

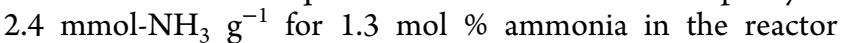
outlet.

\section{STRATEGIES FOR IN SITU PRODUCT REMOVAL FROM PLASMA-CHEMICAL REACTORS}

In this work, we show the beneficial effect of product removal from the plasma phase for ammonia synthesis. This concept could be more widely applicable for plasma-chemical and plasma-catalytic reactions, as decomposition of products is probably a general concern in plasma catalysis. In fact, the reverse reaction in the plasma phase was also demonstrated for $\mathrm{CO}_{2}$ splitting, ${ }^{47}$ methane coupling, ${ }^{48}$ and dry reforming of methane. ${ }^{48}$ Hereafter, we briefly address strategies for product removal from the plasma phase.

Product absorption in, or adsorption on, solid materials is commercially applied in the chemical industry, such as for removal of heavy hydrocarbons from natural gas, as well as for removal of $\mathrm{H}_{2} \mathrm{O}, \mathrm{CO}$, and $\mathrm{CO}_{2}$ from gas streams. Furthermore, sorption-enhanced processes have been proposed for $\mathrm{CO}_{2}$ removal during reforming reactions ${ }^{49,50}$ and during the water gas shift reaction. ${ }^{51}$

In the current work, we demonstrated the use of zeolites for ammonia removal. Likewise, Peng et al. ${ }^{31}$ showed that $\mathrm{MgCl}_{2}$ can be used to absorb ammonia during plasma-chemical ammonia synthesis. A drawback of this is the fact that $\mathrm{MgCl}_{2}$ is converted to $\mathrm{MgN}_{2}$ in the plasma to an important extent, deactivating the sorbent and releasing $\mathrm{Cl}_{2}$ gas. The zeolite used in the current work is chemically stable allowing for multiple adsorption-desorption cycles.

A solid material can also be used as a sacrificial material. ${ }^{52}$ For example, we propose that surplus oxygen from the $\mathrm{CO}_{2}$ splitting reaction can be removed by oxidation of a metal, thereby preventing the oxidation of $\mathrm{CO}$ to $\mathrm{CO}_{2}$. Reactor configurations that can be used in a DBD reactor include a fixed bed configuration and a trickle bed configuration. A fluidized bed configuration may be used in, for instance, a gliding arc reactor, although operating this does not seem not trivial.
The product can also be removed from the plasma phase by using a membrane. For example, Hayakawa et al. ${ }^{53}$ demonstrated hydrogen production from ammonia decomposition in a plasma reactor with and without a membrane. It was observed that the hydrogen yield was almost doubled upon using a membrane for hydrogen removal from the plasma reactor, apparently limiting the backward reaction, in this case ammonia synthesis.

Lastly, the product can be removed in the liquid phase, either by absorbing in a liquid medium or by condensation of the product. Product removal by absorption in a liquid medium was recently demonstrated for nitrogen fixation. Gorbanev et al. ${ }^{54}$ and Hawtof et al. ${ }^{55}$ contacted a nitrogen and steam plasma jet with liquid water, thereby producing ammonia and nitrogen oxides, which were subsequently absorbed in the liquid. Furthermore, Wang et al. ${ }^{56}$ produced oxygenates from $\mathrm{CO}_{2}$ and $\mathrm{H}_{2}$ in a dielectric barrier discharge (DBD) reactor. Upon cooling the reactor wall with a water jacket, methanol and ethanol were liquefied, thereby limiting product decomposition. This resulted in a higher oxygenate yield as compared to the configuration without water cooling.

\section{CONCLUSION}

In this work, we show that in situ adsorption of ammonia with a zeolite during plasma-chemical ammonia synthesis increases the ammonia yield as compared to steady-state plasma-based ammonia synthesis. This can be attributed to ammonia adsorption on the zeolite, thereby suppressing ammonia decomposition in the plasma phase. This improves the energy yield for ammonia synthesis by a factor of 2 , for example, from 1.1 to $2.3 \mathrm{~g}-\mathrm{NH}_{3} \mathrm{kWh}^{-1}$. However, this is still far below the benchmark of $150-200 \mathrm{~g}-\mathrm{NH}_{3} \mathrm{kWh}^{-1}$ required for commercialization of plasma-based ammonia synthesis for small-scale applications ( $\mathrm{kW}$ range). As plasmas cannot penetrate the pores of the zeolite, surface-adsorbed ammonia inside the zeolite pores is protected from reactive plasma species. However, plasma-induced heating reduces the sorbent capacity.

In situ product removal from the plasma phase is of interest for plasma conversions, in general. Therefore, we propose various strategies for product removal from the plasma phase, including product liquefaction, membrane separation, and the use of absorbent or adsorbents.

\section{ASSOCIATED CONTENT}

\section{(1) Supporting Information}

The Supporting Information is available free of charge at https://pubs.acs.org/doi/10.1021/acssuschemeng.1c08467.

Experimental procedures, including materials and preparation, material characterization, plasma characterization, ammonia synthesis and adsorption experiments. Results and discussion, including material characterization, plasma characterization, thermal ammonia TPD study with zeolite 4A, ammonia isotherm for heating effect, and energy cost for zeolite regeneration. (PDF)

\section{AUTHOR INFORMATION}

\section{Corresponding Authors}

Kevin H. R. Rouwenhorst - Catalytic Processes and Materials, MESA+ Institute for Nanotechnology, University of Twente, 7500 AE Enschede, The Netherlands; 
두이.org/0000-0002-2794-199X;

Email: k.h.r.rouwenhorst@utwente.nl

Leon Lefferts - Catalytic Processes and Materials, MESA+ Institute for Nanotechnology, University of Twente, 7500 AE

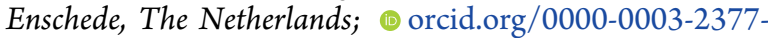
5282; Email: 1.lefferts@utwente.nl

\section{Author}

Samuel Mani - Catalytic Processes and Materials, MESA+ Institute for Nanotechnology, University of Twente, 7500 AE Enschede, The Netherlands

Complete contact information is available at: https://pubs.acs.org/10.1021/acssuschemeng.1c08467

\section{Notes}

The authors declare no competing financial interest.

\section{ACKNOWLEDGMENTS}

This project is cofinanced by TKI-Energie from Toeslag voor Topconsortia voor Kennis en Innovatie (TKI) from the Ministry of Economic Affairs and Climate Policy, The Netherlands. The authors acknowledge K. Altena-Schildkamp for $\mathrm{N}_{2}$ chemisorption and $\mathrm{T}$. Lubbers for XRF analysis.

\section{REFERENCES}

(1) Davis, S. J.; Lewis, N. S.; Shaner, M.; Aggarwal, S.; Arent, D.; Azevedo, I. L.; Benson, S. M.; Bradley, T.; Brouwer, J.; Chiang, Y. M.; Clack, C. T. M.; Cohen, A.; Doig, S.; Edmonds, J.; Fennell, P.; Field, C. B.; Hannegan, B.; Hodge, B. M.; Hoffert, M. L.; Ingersoll, E.; Jaramillo, P.; Lackner, K. S.; Mach, K. J.; Mastrandrea, M.; Ogden, J.; Peterson, P. F.; Sanchez, D. L.; Sperling, D.; Stagner, J.; Trancik, J. E.; Yang, C. J.; Caldeira, K. Net-Zero Emissions Energy Systems. Science (80-.). 2018, 360 (6396), eaas9793 DOI: 10.1126/science.aas9793.

(2) Valera-Medina, A.; Xiao, H.; Owen-Jones, M.; David, W. I. F.; Bowen, P. J. Ammonia for Power. Prog. Energy Combust. Sci. 2018, 69, 63-102.

(3) Andersson, J.; Grönkvist, S. Large-Scale Storage of Hydrogen. Int. J. Hydrogen Energy 2019, 44 (23), 11901-11919.

(4) Götz, M.; Lefebvre, J.; Mörs, F.; McDaniel Koch, A.; Graf, F.; Bajohr, S.; Reimert, R.; Kolb, T. Renewable Power-to-Gas: A Technological and Economic Review. Renew. Energy 2016, 85, 1371-1390.

(5) Rouwenhorst, K. H. R.; Van Der Ham, A. G. J.; Mul, G.; Kersten, S. R. A. Islanded Ammonia Power Systems: Technology Review \& Conceptual Process Design. Renew. Sustain. Energy Rev. 2019, 114, 109339.

(6) Giddey, S.; Badwal, S. P. S.; Munnings, C.; Dolan, M. Ammonia as a Renewable Energy Transportation Media. ACS Sustain. Chem. Eng. 2017, 5 (11), 10231-10239.

(7) Goeppert, A.; Olah, G. A.; Surya Prakash, G. K. Toward a Sustainable Carbon Cycle: The Methanol Economy. In Green Chemistry: An Inclusive Approach; Elsevier Inc., 2017; pp 919-962. DOI: 10.1016/B978-0-12-809270-5.00031-5.

(8) Makepeace, J. W.; He, T.; Weidenthaler, C.; Jensen, T. R.; Chang, F.; Vegge, T.; Ngene, P.; Kojima, Y.; de Jongh, P. E.; Chen, P.; David, W. I. F. Reversible Ammonia-Based and Liquid Organic Hydrogen Carriers for High-Density Hydrogen Storage: Recent Progress. Int. J. Hydrogen Energy 2019, 44 (15), 7746-7767.

(9) Guo, J.; Chen, P. Catalyst: NH3 as an Energy Carrier. Chem. 2017, 3 (5), 709-712.

(10) Avery, W. H. A Role for Ammonia in the Hydrogen Economy. Int. J. Hydrogen Energy 1988, 13 (12), 761-773.

(11) Schüth, F.; Palkovits, R.; Schlögl, R.; Su, D. S. Ammonia as a Possible Element in an Energy Infrastructure: Catalysts for Ammonia Decomposition. Energy Environ. Sci. 2012, 5 (4), 6278-6289.
(12) Green, L. An Ammonia Energy Vector for the Hydrogen Economy. Int. J. Hydrogen Energy 1982, 7 (4), 355-359.

(13) Rouwenhorst, K. H. R.; Krzywda, P. M.; Benes, N. E.; Mul, G.; Lefferts, L. Ammonia Production Technologies. In Techno-Economic Challenges of Green Ammonia as Energy Vector; Bañares-Alcántara, R. Valera-Medina, A., Eds.; Elsevier Science Publishing Co., Inc., 2020; pp 41-84 DOI: 10.1016/B978-0-12-820560-0.00004-7.

(14) Rouwenhorst, K. H. R.; Krzywda, P. M.; Benes, N. E.; Mul, G.; Lefferts, L. Ammonia, 4. Green Ammonia Production. In Ullmann's Encyclopedia of Industrial Chemistry; Wiley, 2020. DOI: 10.1002/ 14356007.w02_w02.

(15) Van Geem, K. M.; Galvita, V. V.; Marin, G. B. Making Chemicals with Electricity. Science (80-.). 2019, 364 (6442), 734735 .

(16) Peng, P.; Chen, P.; Schiappacasse, C.; Zhou, N.; Anderson, E.; Chen, D.; Liu, J.; Cheng, Y.; Hatzenbeller, R.; Addy, M.; Zhang, Y.; Liu, Y.; Ruan, R. A Review on the Non-Thermal Plasma-Assisted Ammonia Synthesis Technologies. J. Clean. Prod. 2018, 177, 597609.

(17) Hong, J.; Prawer, S.; Murphy, A. B. Plasma Catalysis as an Alternative Route for Ammonia Production: Status, Mechanisms, and Prospects for Progress. ACS Sustain. Chem. Eng. 2018, 6 (1), 15-31. (18) Rouwenhorst, K. H. R.; Engelmann, Y.; Van 't Veer, K.; Postma, R. S.; Bogaerts, A.; Lefferts, L. Plasma-Driven Catalysis: Green Ammonia Synthesis with Intermittent Electricity. Green Chem. 2020, 22 (19), 6258-6287.

(19) Carreon, M. L. Plasma Catalytic Ammonia Synthesis: State of the Art and Future Directions. J. Phys. D. Appl. Phys. 2019, 52 (48), 483001.

(20) Rouwenhorst, K. H. R.; Burbach, H. G. B.; Núñez Paulí, J.; Vogel, D. W.; Geerdink, B.; Lefferts, L. Plasma-Catalytic Ammonia Synthesis beyond Thermal Equilibrium on Ru-Based Catalysts in Non-Thermal Plasma. Catal. Sci. Technol. 2021, 11 (9), 2834-2843.

(21) Gorbanev, Y.; Engelmann, Y.; van't Veer, K.; Vlasov, E.; Ndayirinde, C.; Yi, Y.; Bals, S.; Bogaerts, A. Al2O3-Supported Transition Metals for Plasma-Catalytic NH3 Synthesis in a DBD Plasma: Metal Activity and Insights into Mechanisms. Catalysts 2021, 11 (10), 1230.

(22) Mehta, P.; Barboun, P.; Engelmann, Y.; Go, D. B.; Bogaerts, A.; Schneider, W. F.; Hicks, J. C. Plasma-Catalytic Ammonia Synthesis Beyond the Equilibrium Limit. ACS Catal. 2020, 10 (12), 67266734.

(23) Kim, H.-H.; Teramoto, Y.; Ogata, A.; Takagi, H.; Nanba, T. Atmospheric-Pressure Nonthermal Plasma Synthesis of Ammonia over Ruthenium Catalysts. Plasma Process. Polym. 2017, 14 (6), 1600157.

(24) Rouwenhorst, K. H. R.; Lefferts, L. Feasibility Study of PlasmaCatalytic Ammonia Synthesis for Energy Storage Applications. Catalysts 2020, 10 (9), 999.

(25) Kim, H.-H.; Teramoto, Y.; Ogata, A.; Takagi, H.; Nanba, T. Plasma Catalysis for Environmental Treatment and Energy Applications. Plasma Chem. Plasma Process. 2016, 36 (1), 45-72.

(26) van 't Veer, K.; Engelmann, Y.; Reniers, F.; Bogaerts, A. PlasmaCatalytic Ammonia Synthesis in a DBD Plasma: Role of the MicroDischarges and Their Afterglows. J. Phys. Chem. C 2020, 124 (42), 22871-22883.

(27) Navascués, P.; Obrero-Pérez, J. M.; Cotrino, J.; González-Elipe, A. R.; Gómez-Ramírez, A. Isotope Labelling for Reaction Mechanism Analysis in DBD Plasma Processes. Catalysts 2019, 9 (1), 45.

(28) Navascués, P.; Obrero-Pérez, J. M.; Cotrino, J.; González-Elipe, A. R.; Gómez-Ramírez, A. Unraveling Discharge and Surface Mechanisms in Plasma-Assisted Ammonia Reactions. ACS Sustain. Chem. Eng. 2020, 8 (39), 14855-14866.

(29) Helminen, J.; Helenius, J.; Paatero, E.; Turunen, I. Adsorption Equilibria of Ammonia Gas on Inorganic and Organic Sorbents at 298.15 K. J. Chem. Eng. Data 2001, 46 (2), 391-399.

(30) Helminen, J.; Helenius, J.; Paatero, E.; Turunen, I. Comparison of Sorbents and Isotherm Models for NH3-Gas Separation by Adsorption. AIChE J. 2000, 46 (8), 1541-1555. 
(31) Peng, P.; Chen, P.; Addy, M.; Cheng, Y.; Anderson, E.; Zhou, N.; Schiappacasse, C.; Zhang, Y.; Chen, D.; Hatzenbeller, R.; Liu, Y.; Ruan, R. Atmospheric Plasma-Assisted Ammonia Synthesis Enhanced via Synergistic Catalytic Absorption. ACS Sustain. Chem. Eng. 2019, 7, 100-104.

(32) Gorky, F.; Carreon, M. A.; Carreon, M. L. Experimental Strategies to Increase Ammonia Yield in Plasma Catalysis over LTA and BEA Zeolites. IOP SciNotes 2020, 1 (2), 024801.

(33) Shah, J. R.; Gorky, F.; Lucero, J.; Carreon, M. A.; Carreon, M. L. Ammonia Synthesis via Atmospheric Plasma-Catalysis: Zeolite 5A a Case of Study. Ind. Eng. Chem. Res. 2020, 59, 5167.

(34) Rouwenhorst, K. H. R.; Kim, H.-H.; Lefferts, L. Vibrationally Excited Activation of $\mathrm{N} 2$ in Plasma-Enhanced Catalytic Ammonia Synthesis: A Kinetic Analysis. ACS Sustain. Chem. Eng. 2019, 7 (20), 17515-17522.

(35) Itadani, A.; Tanaka, M.; Mori, T.; Torigoe, H.; Kobayashi, H.; Kuroda, Y. Potential for Fixation of N2 at Room Temperature Utilizing a Copper-Ion-Exchanged MFI-Type Zeolite as an Adsorbent: Evaluation of the Bond Dissociation Energy of Adsorbed $\mathrm{N} \equiv \mathrm{N}$ and the Bond Strength of the $\mathrm{Cu}+-\mathrm{N}(\equiv \mathrm{N})$ Species. J. Phys. Chem. Lett. 2010, 1 (15), 2385-2390.

(36) Bogaerts, A.; Zhang, Q.; Zhang, Y.; Van Laer, K.; Wang, W. Burning Questions of Plasma Catalysis: Answers by Modeling. Catal. Today 2019, 337, 3-14.

(37) Roland, U.; Holzer, F.; Kopinke, F. D. Improved Oxidation of Air Pollutants in a Non-Thermal Plasma. Catal. Today 2002, 73 (34), 315-323.

(38) Zhang, Y. R.; Van Laer, K.; Neyts, E. C.; Bogaerts, A. Can Plasma Be Formed in Catalyst Pores? A Modeling Investigation. Appl. Catal. B Environ. 2016, 185, 56-67.

(39) Zhang, Q. Z.; Bogaerts, A. Propagation of a Plasma Streamer in Catalyst Pores. Plasma Sources Sci. Technol. 2018, 27 (3), 035009.

(40) Bogaerts, A.; Tu, X.; Whitehead, J C.; Centi, G.; Lefferts, L.; Guaitella, O.; Azzolina-Jury, F.; Kim, H.-H.; Murphy, A. B; Schneider, W. F; Nozaki, T.; Hicks, J. C; Rousseau, A.; Thevenet, F.; Khacef, A.; Carreon, M. The 2020 Plasma Catalysis Roadmap. J. Phys. D. Appl. Phys. 2020, 53, 443001.

(41) Kim, H.-H.; Teramoto, Y.; Negishi, N.; Ogata, A. A Multidisciplinary Approach to Understand the Interactions of Nonthermal Plasma and Catalyst: A Review. Catal. Today 2015, $256,13-22$.

(42) Liu, C. Y.; Aika, K.-I. Ammonia Adsorption on Ion Exchanged Y-Zeolites as Ammonia Storage Material. J. Japan Pet. Inst. 2003, 46 (5), 301-307.

(43) Takeuchi, M.; Tsukamoto, T.; Kondo, A.; Matsuoka, M. Investigation of $\mathrm{NH} 3$ and NH4+ Adsorbed on ZSM-5 Zeolites by near and Middle Infrared Spectroscopy. Catal. Sci. Technol. 2015, 5 (9), 4587-4593.

(44) Neyts, E. C. Plasma-Surface Interactions in Plasma Catalysis. Plasma Chem. Plasma Process. 2016, 36 (1), 185-212.

(45) Jidenko, N.; Bourgeois, E.; Borra, J. P. Temperature Profiles in Filamentary Dielectric Barrier Discharges at Atmospheric Pressure. J. Phys. D. Appl. Phys. 2010, 43 (29), 295203.

(46) Giammaria, G.; van Rooij, G.; Lefferts, L. Plasma Catalysis: Distinguishing between Thermal and Chemical Effects. Catalysts 2019, 9 (2), 185.

(47) Uytdenhouwen, Y.; Bal, K.M.; Michielsen, I.; Neyts, E.C.; Meynen, V.; Cool, P.; Bogaerts, A. How Process Parameters and Packing Materials Tune Chemical Equilibrium and Kinetics in Plasma-Based CO2 Conversion. Chem. Eng. J. 2019, 372, 1253-1264.

(48) Uytdenhouwen, Y.; Bal, K. M.; Neyts, E. C.; Meynen, V.; Cool, P.; Bogaerts, A. On the Kinetics and Equilibria of Plasma-Based Dry Reforming of Methane. Chem. Eng. J. 2021, 405, 126630.

(49) Shokrollahi Yancheshmeh, M.; Radfarnia, H. R.; Iliuta, M. C. High Temperature CO2 Sorbents and Their Application for Hydrogen Production by Sorption Enhanced Steam Reforming Process. Chem. Eng. J. 2016, 283, 420-444.

(50) Dou, B.; Wang, C.; Song, Y.; Chen, H.; Jiang, B.; Yang, M.; Xu, Y. Solid Sorbents for In-Situ CO2 Removal during Sorption-

Enhanced Steam Reforming Process: A Review. Renew. Sustain. Energy Rev. 2016, 53, 536-546.

(51) Van Selow, E. R.; Cobden, P. D.; Verbraeken, P. A.; Hufton, J. R.; Van Den Brink, R. W. Carbon Capture by Sorption-Enhanced Water-Gas Shift Reaction Process Using Hydrotalcite-Based Material. Ind. Eng. Chem. Res. 2009, 48 (9), 4184-4193.

(52) Rouwenhorst, K. H. R.; van Rooij, G. J.; Lefferts, L. PlasmaAssisted Conversion of $\mathrm{CO}_{2}$. In Engineering Solutions for $\mathrm{CO}_{2}$ conversion: A Global Challenge; Reina, T., Odriozola, J. A., ArellanoGarcia, H., Eds.; Wiley-VCH Verlag GmbH, 2022; pp 429-462. DOI: $10.1002 / 9783527346523 . c h 18$.

(53) Hayakawa, Y.; Kambara, S.; Miura, T. Hydrogen Production from Ammonia by the Plasma Membrane Reactor. Int. J. Hydrogen Energy 2020, 45 (56), 32082-32088.

(54) Gorbanev, Y.; Vervloessem, E.; Nikiforov, A.; Bogaerts, A. Nitrogen Fixation with Water Vapor by Non- Equilibrium Plasma: Towards Sustainable Ammonia Production. ACS Sustain. Chem. Eng. 2020, 8, 2996.

(55) Hawtof, R.; Ghosh, S.; Guarr, E.; Xu, C.; Sankaran, R. M.; Renner, J. N. Catalyst-Free, Highly Selective Synthesis of Ammonia from Nitrogen and Water by a Plasma Electrolytic System. Asian J. Chem. 2019, 5 (1), eaat5778.

(56) Wang, L.; Yi, Y.; Guo, H.; Tu, X. Atmospheric Pressure and Room Temperature Synthesis of Methanol through Plasma-Catalytic Hydrogenation of CO2. ACS Catal. 2018, 8 (1), 90-100.

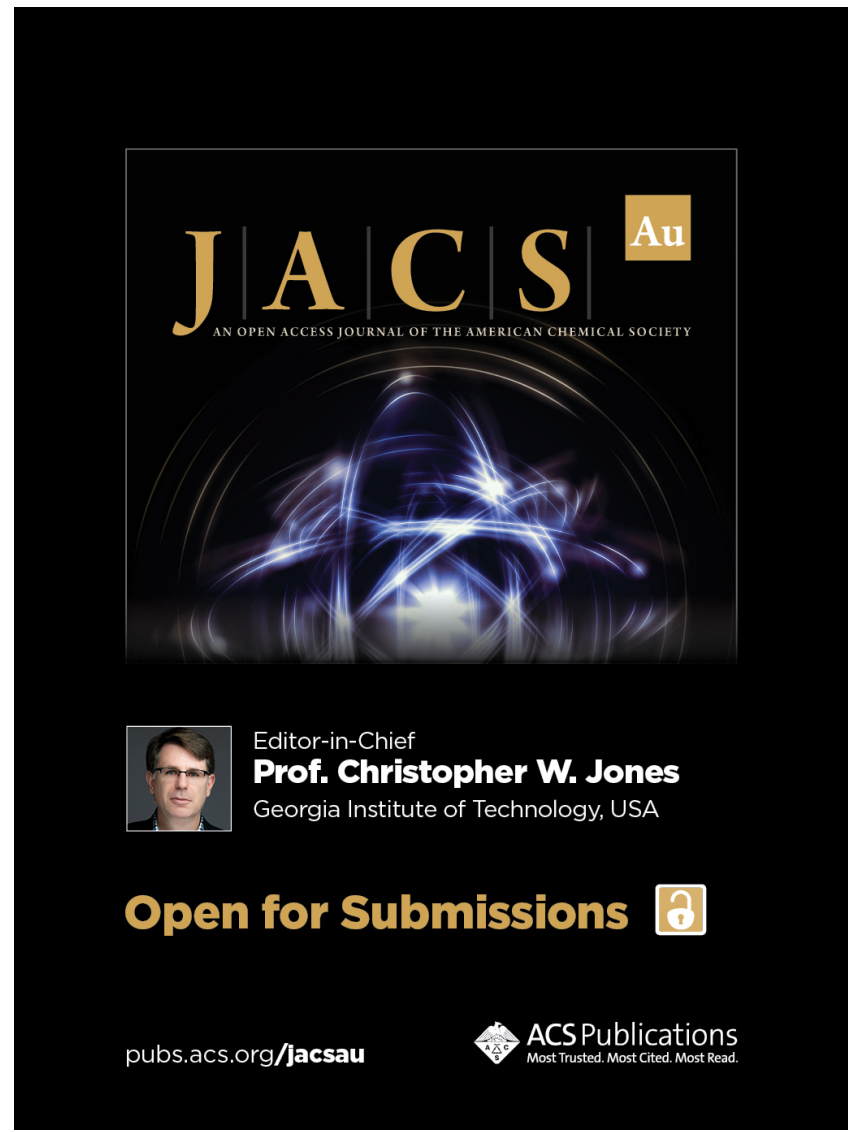

